\title{
Editorial 24/1: Electronic Markets and practice-orientation
}

\author{
Rainer Alt $\cdot$ Hubert Österle
}

Published online: 23 February 2014

(C) Institute of Information Management, University of St. Gallen 2014

Dear readers of Electronic Markets,

The last issue of Electronic Markets included a longitudinal review of research from contributions published at the Bled eConference since 1988. This paper observed an evolution of topics regarding the application of information technology (IT) to interorganizational processes. While the first phase from the mid-1980s until the mid-1990s focused on applying electronic data interchange (EDI) technologies, the second from the mid1990s until the mid-2000s contributed to the more businessoriented development of electronic business and, finally, the third on the electronic interaction between organizations and also individuals on a more general level since the mid-2000s. Remarkably, the authors observe a gap between the topics discussed in the academic papers and the developments occurring in practice and note that "Given that there is a delay of 2-3 years before papers gain citations, the vast majority of the thousands of subsequent papers - even if they were written in a manner accessible to professionals, managers and/or executives - were published too late to have any useful impact on early adopters or even on the early majority." (Clarke \& Pucihar 2013, 276). We believe that this statement has three dimensions which are critical for academic research.

First, it recognizes that academic publications are generally not written for readers in practice. The gap between academic and practice publications is not limited to the wording or the layout used in either format, but - more importantly - it is grounded in the predominant perspective of both audiences.

\footnotetext{
R. Alt $(\triangle)$

University of Leipzig, Grimmaische Str. 12,

04109 Leipzig, Germany

e-mail: rainer.alt@uni-leipzig.de

H. Österle

University of St. Gallen, Müller-Friedberg-Str 8,

9000 St. Gallen, Switzerland

e-mail: hubert.oesterle@unisg.ch
}

While researchers aim at carefully developing and answering their research question(s) by applying a specific research methodology, individuals working in line functions (other than research) or who fill management positions are often only interested in the findings of a research article and their implications for practice. Contrary to academics who strive for the justification of their procedure and the generalization of their findings, the practice community is interested in results and recommendations which provide insight into problems for their particular (line) function or company in general. Thus, the dissemination of academic research into practice calls for formats that - if necessary allow to trace back how results were obtained and places more detailed emphasis on the implications of the findings for practice.

Second, the statement implies a latency of academic research compared to the application of a certain phenomenon in practice. For example, businesses might adopt new technologies before these are described, discussed or analyzed in academic conferences or journals. From the perspective of the popular hype cycle of Gartner (see Fenn \& Raskino 2008, 65ff) shown in Fig. 1 this means that new technologies have already passed the first phase ("innovation trigger") and presumably also the second phase ("peak of inflated expectations"). Under the assumption of the latency of academic discourse, publications would only become available when innovations have already entered their third phase ("trough of disillusionment"). Insights obtained in research that guide businesses in applying new technologies might be valuable for second movers, but emerge too late for first (or early) movers which strongly influence the development of innovations. This means that academic research not only needs to be published faster in physical and electronic forms, but also that researchers need to target emerging technologies in their work while these are still in their early stages of development (i.e. phases 1 and 2 in Fig. 1). 


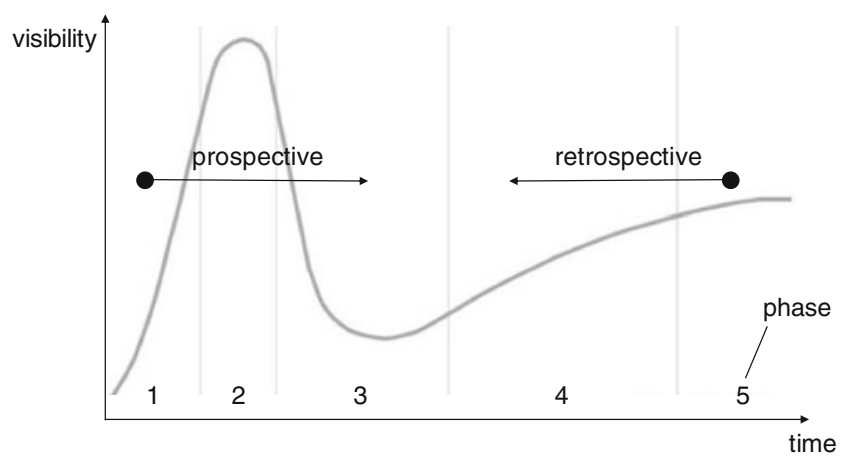

Fig. 1 Phases of the hype cycle

Third, the research methods applied in academic papers need to be aligned to an innovation's development stage. Research indicates that "financial-based empirical research is not likely to be a part of research until or after the plateau of enlightenment since not enough companies have implemented the technology to gather meaningful samples of data [and that ...] design science $[\ldots]$ is possibly the only feasible kind of research at the trigger point in the hype cycle, other than expert opinion" (O'Leary 2008, 246f). Following the hype cycle phases three different types of papers are suggested (O'Leary 2008, 247): prototypes and behavioral design in phases 1 and 2, case studies and behavioral analyses in phases 2 and 3 as well as quantitative financial-based empirical research in phases 4 and 5 . The general attitude to equal academic research with one particular positivistic research style has been questioned in many contributions on the "rigor or relevance" paradigm and the intent to establish design science as an accepted scientific methodology (Gregor \& Hevner 2013) nurtures a "fertile soil" for prospective research that is called for in phases 1 and 2. As also indicated in Fig. 1 this is not synonymous with neglecting empirical research, but it should be emphasized that this research style lends itself more for retrospective research questions (Österle et al. 2011).

These three aspects have also been discussed in the Editorial team and among editors of Electronic Markets. One aspect was the decision to systematically measure the efficiency of journal processes which includes the ongoing monitoring of key metrics, such as the "time from submission to first decision' for all submissions as well as the 'time from submission to online first publication' for accepted papers. At the latest annual meeting of the Electronic Markets' Editorial Board held at the International Conference on Information Systems (ICIS 2013) in Milan, it was reported that the average time from submission and acceptance amounted to 38 weeks in 2013 and that Electronic Markets aims at providing authors that submit their work to Electronic Markets a first feedback within two weeks as to whether the paper is suitable from a formal point of view and whether it bears ample potential of being accepted within the review process. This is mainly due to the fact that reviewers are one of the most valuable resources for an academic journal and that Electronic Markets endeavors to constructively develop promising submissions for publication. Depending on the scope of the required revisions as well as the responsiveness regarding timing and content on behalf of the authors, this process may require several iterations and all measures aiming at streamlining this process have to ensure that quality standards are not affected. It was also decided that Electronic Markets intends at providing feedback for papers that proceed to the review process regarding the first decision back to the authors within an average of sixty days.

Another important organizational change that was also agreed upon by participants at the Editorial Board Meeting was establishing an Advisory Board consisting of executives from practice. We plan to regularly discuss the various challenges of practice-orientation with the members of this board who contribute practical perspectives from various disciplines. In view of the three above mentioned aspects, Electronic Markets hopes for support regarding the investigation of new formats for publishing the results of academic research, suggestions for new upcoming topics during the 'innovation trigger' phase which might be promising for organizing special issues and the like, and ideas of how to further encourage design science research in Electronic Markets. We are happy that ten professionals have agreed to participate in the Electronic Markets Advisory Board: Ulrich Bäumer, partner at the legal services firm Osborne Clarke, Peter Dengate Thrush, Executive Chairman of the Internet registering company Top Level Domain Holdings, Chris Disspain, Chief Executive Officer of another registering company .au Domain Administration, Werner Dorfmeister, Chief Technology Officer Enterprise Services at Hewlett Packard, Christian Eggenberger-Wang, an executive consultant at IBM Global Technology Services, Veni Markovski, vice-president at ICANN responsible for Russia and Eastern Europe, Rajasekhar Ramaraj, a founder of the India-based provider of IT services Sify Technologies, Frank Riemensperger, Managing Director at Accenture in Germany, Antje Stobbe, director at Deutsche Bank, and Paul Twomey, Managing Director of the IT consulting firm Argo Pacific. We welcome these personalities to Electronic Markets and look forward to the discussions on practice-orientation within the Advisory Board.

This leads us to the latest changes in the Editorial Board. First, we have to acknowledge that Andreas Herrmann from the University of St.Gallen in Switzerland, and Jože Gričar from the University of Maribor in Slovenia who was also the founder of the Bled eConference, have decided to step down from the Editorial Board. We would like to thank them both for their dedication and their contributions to Electronic Markets in the past. Second, we are happy that several esteemed colleagues have followed the invitations that were decided upon during the Editorial Board Meeting in Milan. Steven Bellman from Murdoch University in Australia, has been a 
member of our Editorial Board for many years already and has agreed to join Electronic Markets as Associate Editor. The new Editorial Board Members are Volker Bach from Steinbeis University Berlin and SAP in Germany, Ricardo ColomoPalacios from Universidad Carlos III de Madrid in Spain, Yi Ding from Georgia Gwinnett College in the US, Marianna Sigala from the University of the Aegean in Greece, and Martin Smits from Tilburg School of Economics and Management in The Netherlands. All new board members have already contributed to Electronic Markets in numerous reviews and we highly appreciate that they have decided to intensify their relationship with Electronic Markets. In particular, Steven Bellman and Yi Ding also qualified as 'Outstanding Reviewers' in 2013. These achievements were awarded for the first time during the Editorial Board Meeting based on the number of reviews delivered to EM in 2013 and a set of quality criteria. Our Associate Editor, Harry Bouwman from the University of Technology in Delft, The Netherlands, our editorial board member Ulrike Lechner from Universität der Bundeswehr München in Germany, and Frédéric Georges Thiesse from the University of Würzburg in Germany are the remaining winners of the five reviewer awards. We congratulate all of them and hope for continuing enthusiasm for Electronic Markets.

Last but not least, the present issue of Electronic Markets includes a collection of six general research papers that have improved during the reviews and the guidance of the involved Associate Editors and reviewers. We would like to thank all of them and trust that you enjoy reading these articles. Since an overall theme is not available the contributions show a broad variety of topics that are relevant in the electronic markets' field. At the same time they also mirror the broad use of the term 'electronic markets' (see EM 2014).

The first article on "Designing for mobile value co-creation - the case of travel counselling" is authored by Susanne Schmidt-Rauch and Gerhard Schwabe. They present an example of how mobile services may complement existing interaction channels that customers use during the various steps of their travel cycle.

The second article is an enhanced version of a paper published at the Hawaii International Conference on System Sciences. Daniel Beimborn uses game theory to investigate "The stability of cooperative sourcing coalitions" and contributes towards understanding the costs and benefits when sourcing services in a cooperative setting. The paper develops a formal cost allocation and benefit model that also points at threats for managers in these multi-actor constellations.

The third article titled "A service innovation evaluation framework for tourism e-commerce in China based on BP neural network" is authored by Lifang Peng and Lingling Lai. They apply a neural network model to assess the effectiveness of service innovation in electronic commerce. The study is conducted in the area of tourism in China and presents an interesting evaluation framework and index system that also provides insights for companies operating electronic commerce sites.

Another article from the Chinese region analyzes "The impact of early XBRL adoption on analysts' forecast accuracy". The authors Chunhui Liu, Lee Jian Yao, Choon Ling Sia, and Kwok Kee Wei examine the ability of the eXtensible Business Reporting Language (XBRL) as a common data standard to improve information quality and information sharing in the value chain.

The fifth article "Understanding Chinese users' continuance intention toward online social networks: an integrative theoretical model" is authored by Yuan Sun, Ling Liu, Xinmin Peng, Yi Dong, and Stuart J. Barnes. It develops an integrated model to understand the continued contribution of users in online social networks.

The issue finishes with an article on the "Relationship of trustworthiness and relational benefit in electronic catalog markets". Haixia Gao and Dawei Liu propose a model to assess the relational benefits and the development of trustworthiness in regard to possible impacts on relational loyalty and satisfaction. The paper contributes to the discussion on how economic and social benefits may influence trustworthiness in electronic markets.

Finally, Electronic Markets welcomes your thoughts on practice-orientation and how academic journals in a field that undoubtedly has high relevance in practice might become more interesting and relevant for practitioners.

Best regards from Leipzig and St. Gallen,

Rainer Alt

Hubert Österle

\section{References}

Clarke, R., \& Pucihar, A. (2013). Electronic interaction research 19882012 through the lens of the Bled eConference. Electronic Markets, 23(4), 271-283.

EM, Scope, Website of Electronic Markets (EM) journal, http://www. electronicmarkets.org/about-em/scope/, February 2, 2014.

Fenn, J., \& Raskino, M. (2008). Mastering the hype cycle: how to choose the right innovation at the right time. Boston (MA): Harvard Business Press.

Gregor, S., \& Hevner, A. S. (2013). Positioning and presenting design science research for maximum impact. MIS Quarterly, 37(2), 337 355.

O'Leary, D. E. (2008). Gartner's hype cycle and information system research issues. International Journal of Accounting Information Systems, 9(4), 240-252.

Österle, H., et al. (2011). Memorandum on design-oriented information systems research. European Journal of Information Systems, 20(1), $7-10$. 